\title{
Gender in academic recruitment and selection
}

\author{
Mathias Wullum Nielsen
}

\section{Introduction}

Three social processes interact to produce gender inequalities in academic recruitment and selection: (i) institutional decoupling among hiring managers; (ii) standardisation of scientific performance assessments; and (iii) symbolic boundary work in relation to gender. All three are shaped by the organisational contexts in which they operate and act to reinforce gender inequalities in recruitment and selection. Not all of them are adequately explained by unconscious bias. Gender bias assumes many different forms in academia, including homophily (the tendency for people to seek out or be attracted to those who are similar to themselves) (Nielsen 2016). In networks of academic recruiters it may be incorporated into seemingly objective criteria for evaluating research performance (Nielsen 2017b, 2018). Systemic bias is noted in the cultural narratives of academic managers, in which ideas about women's attributes and qualities as researchers are separated from the predominant organisational image of the ideal academic (Nielsen 2017a) (see Chapter 4). This chapter outlines each of the three social processes with examples of possible 'fixes' that could help to mitigate the gender biases at play in academic recruitment and selection.

Unconscious bias is commonly noted in research and policy discussions on gender in academic recruitment and selection to explain cognitive errors made by well-intentioned decision-makers that put women and minorities at a disadvantage (Bielby 2013). Unconscious bias represents an important framework for understanding aspects of gendered academic recruitment (see Chapter 9). Due to its restricted focus on cognitive processes and snap-judgements, unconscious bias tends to individualise the problem of gender discrimination leaving aside the more complicated, sociological questions about the gendered structures, hierarchies and cultures of academia (Nielsen 2017a). Two influential studies on unconscious bias in academic hiring demonstrate this point.

In the first, Moss-Racusin et al (2012) asked 127 professors in US universities to rate an identical application, randomly assigned either a male or female name, for a position as laboratory manager. The evaluators, on average, rated the male applicant as more competent and hireable than the identical female candidate. 
They also offered a higher starting salary and more career mentoring for the male candidate. In the second study, Williams and Ceci (2015) asked 873 US tenured staff to evaluate narrative summaries describing female and male applicants for assistant professorships. In direct conflict with the results of Moss-Racusin and colleagues, Williams and Ceci (2015) found that participants were twice as likely to prefer a female candidate over a male candidate with equivalent qualifications.

It is crucial to emphasise the differences in how the two experiments were carried out. In the Moss-Racusin study, the participants were led to believe that they were providing feedback for a real student to help his or her career development. In the Williams and Ceci study, the participants were asked to rank three candidates. They knew that the candidates were fictitious, they knew they were selecting between male and female candidates and that both a male and female candidate were described as excellent in the narrative summaries. Some critics have argued that this set-up may have triggered a social-desirability bias among the participants in the Williams and Ceci study. In a hypothetical scenario, with an equally excellent male and female candidate, the participants may have been prone to pick the female candidate in order to appear unbiased in their assessments (Williams and Smith 2015; Haynes and Sweedler 2015). Moss-Racusin et al (2012) overcame this problem by creating a more realistic scenario and asking each participant to rate only one subject. However, their study used ratings of hireability for lower-ranked, non-tenured positions, which may differ considerably from the considerations involved when recruiting tenured staff.

Both studies also shared another important limitation. They were too focused on what was going on 'inside the heads' of decision-makers and thereby lost sight of the organisational contexts that shape most hiring decisions in academia (Bielby $2000,2013)$. To fully understand the gender dynamics at play in academic hiring, researchers need to examine the social and organisational contexts in which these gender dynamics play out. The research focus could be expanded to capture what happens before evaluators make their final judgements on who to hire (Nielsen 2016) and how contextual factors amplify gender bias in recruitment and selection (Correll 2017).

\section{Decoupling in academic recruitment and selection}

The first social process concerns institutional decoupling in academic recruitment and selection. As demonstrated in this section, academic managers can exploit loopholes to reduce external constraints on their hiring practices and increase managerial efficiency at department level. To borrow a term from neo-institutionalist sociology, these academic managers sometimes 'decouple' their hiring practices from formal organisational rules and procedures to make recruitment and selection 'run smoothly' (Meyer and Rowan 1977). The challenge is that this form of decoupling allows managers to make hiring decisions based on personal idiosyncrasies and social networks, with potentially negative consequences for gender equality (Reskin and McBrier 2000). 
The discussion of institutional decoupling in recruitment and selection primarily draws on a case study conducted at Aarhus University in Denmark between 2013 and 2015 (Nielsen 2015a, 2016). The study was based on recruitment data from more than 1,000 associate and full professorial appointments, and interviews with 24 of the 27 department heads at the university. Aarhus University is one of Denmark's largest, with more than 40,000 students, 4,000 staff members employed on research contracts and 27 departments. At the time of the study, women comprised 15 per cent of full professors, 32 per cent of associate professors and 43 per cent of the postdocs and assistant professors at the university. In the Danish university system, department heads take on the primary responsibility for coordinating and managing the hiring of associate and full professors in coordination with the faculty deans. The role of the external assessment committees that review the applicants is limited to identifying qualified candidates.

Following a 2003 reform of the Danish university system, department heads went from being elected by their peers to being appointed by the faculty deans. They were also assigned new administrative duties including responsibilities for department budgets, strategic planning, recruitment and selection (Degn 2015). In the current university model, departments are run more like small businesses and this, arguably, places conflicting demands on department heads in recruitment and selection. The meritocratic ideal of hiring the best and the brightest while being objective, fair and transparent is sometimes at odds with an efficiency driven rationale for making recruitment and selection run 'fast, cheap and smooth'.

The ideal of the meritocracy is in the DNA of the modern university (Van den Brink and Benschop 2012; López and O'Connor 2019). In interviews with department heads at Aarhus University, many of them described their recruitment activities as based on meritocratic principles noting: 'We only look at qualifications'; 'all of our researchers are hired on their merits'; 'for us it's all about getting the best candidate'. These quotes demonstrate a strong institutionalised belief in meritocracy, not only as an ideal that recruiters aspire to, but as a belief in how recruitment and selection practices actually work at their university. Socialpsychological experiments suggest that deeply institutionalised meritocratic beliefs can be detrimental to gender equality. The work of Castilla and Bernard (2010) shows that performance assessments are more likely to be gender biased in organisations that explicitly pride themselves in being meritocratic. They explain their findings by arguing that 'in contexts in which people are led to feel that they are unbiased, fair, or objective, they are more likely to behave in biased ways' (Castilla and Bernard 2010, 547; see also Uhlmann and Cohen 2007).

Analysis of more than 1,000 professorial appointments at Aarhus University also demonstrates discrepancies in the adherence to meritocratic principles by department heads. In the period from 2004 to 2013, 19 per cent of new associate and full professors were hired through 'closed' procedures without advertisement, usually with only one applicant. Despite the university's efforts to align recruitment practices with the meritocratic principle of open competition, the use of closed procedures increased from 8 per cent of associate and full professorship appointments in 2004-2008 to 30 per cent in 2009-2013. This trend was 
not unique to Aarhus university. In the period 2011-2013, 17 per cent of full professorship and 21 per cent of associate professorship appointments in Denmark were made through closed procedures (Staahle 2014). Current research on gender dynamics in recruitment and selection suggests that such informal hiring practices are at high risk of reinforcing gender inequalities (Acker 2006; Bielby 2000; Reskin and McBrier 2000). This was also true at Aarhus University. In a statistical analysis that adjusted for scientific field, position level and number of male and female applicants per position, the likelihood of women being appointed to associate or full professorship was 79 per cent higher when appointments took place under open, publicly advertised, rather than closed procedures. The gender imbalance in 'closed hirings' was most notable at the full professor level, where women comprised 12 per cent of applicants. In contrast, women made up 23 per cent of the applicants for full professorships with 'open' recruitment. Note here that appointments under closed procedures usually have just one single applicant and represent a form of pre-selection. Similar trends have been observed for the other Danish universities. For example, the University of Copenhagen hired 10 per cent women to full professorships through closed procedures in the period 2011 to 2013 and 32 per cent through open procedures (Staahle 2014).

The analysis of recruitment data also shows that for associate and full professorships at Aarhus University a significant share attracted just a single applicant. From 2004 to 2013, 47 per cent of vacancies for full professorships and 37 per cent of vacancies for associate professorships received only one application and the proportion of appointments with only one applicant increased over time. This pattern also reflected a broader issue in Danish academia. In the period 20112013, 31 per cent of recruitment calls for full professorships and 17 per cent of recruitment calls for associate professorships at Danish universities had only one applicant (Staahle 2014).

While women and men at Aarhus University had approximately the same likelihood of being appointed in single applicant competitions, women may still be at a disadvantage in such scenarios, especially at the early career stages. In general, female postdocs and assistant professors at Aarhus University were far less likely than men to apply for vacancies at the associate professorship level. The relative difference between women's share of potential candidates occupying postdocs or assistant professorships and women's share of applicants for associate professorships ranged from 19 per cent to 41 per cent per year for the period 2008 to 2012.

Interviews with department heads at Aarhus University provided the opportunity to ask about the prevalent use of closed hiring procedures and single-applicant appointments allowing a deeper understanding of the sentiments underpinning the different hiring practices used and how gender bias may have shaped such practices. Several interviewees acknowledged that they had sometimes used narrow job profiles to limit the expected number of applicants for vacancies:

'Sometimes you can, and this is no secret, you can narrow it down in such a way that people will almost recognise. . listen, there's probably only one or two persons in this country qualified for this position. That happens once 
in a while. It does . . in principle it's not the right way to do it. You ought to announce it in such a way that many are provided with an opportunity to apply' (department head).

(Nielsen 2016a)

Three different arguments emerged for using narrow job profiles in recruitment. The first was related to strategic planning and the specificity of the overall tasks and subject areas covered by a department. For example, recruiters may need to fill a specific gap in relation to research and teaching activities. A second issue concerned the time and costs of hiring external candidates. Hiring processes typically expand over longer time periods and increase administrative burdens at department level. A third issue related to departmental budgets: attracting applicants from all over the world may result in a situation where the department ends up with extra salary expenses, since it is cheaper to promote a local employee than it is to bring in a new external candidate for a position.

Advertisements often involved a preceding identification or screening of promising local candidates:

I spend a lot of time figuring out which of the assistant professors and postdocs we're going to promote for associate professorships and who to promote for full professorships. One of our most recent professor appointments . . . well, we had a very, very good associate professor and I've known him for years . . . and I've wondered . . it's actually unfair that he didn't get a professorship ... and he's not that young anymore. But his research is very good. . . In that situation, we announced the job profile narrowly, since we had a particular interest in him. And we ended up with only two applicants' (department head).

(Nielsen 2016a)

In some cases, this form of pre-screening may have reduced local candidates' interest in applying for a position, since they would be aware that the 'right person for the job' has already been identified. A position is announced openly, but it fits the career progression of a particular scholar and may already have a local name on it. Unfortunately, gender bias tends to flourish in such scenarios. As demonstrated in pioneering gender research on recruitment and selection in academia (Husu 2000; Van den Brink 2010; Van den Brink and Benschop 2012), such informal hiring scenarios depend largely on the potential candidates' reputation and visibility to the local gatekeepers, which may put women at a disadvantage. As noted by Husu, these are the types of hiring scenarios that where:

subtle, hardly conscious, and hidden processes [may be] at play, which have to do with male networks, the mutual support systems of men, and the relative invisibility of women in regard to their male colleagues. 
But what is the justification for closed procedures? It was more difficult to obtain clear answers from the department heads on how and why this type of hiring practice was used. Several of them noted that external funding could result in exemptions from the university's formal hiring rules. Additionally, leaders of externally funded projects are allowed to hire temporary professorships for their projects under closed procedures. In large-scale projects, these temporary positions can be extended to permanent professorships. University managers condone such exemptions to ensure that funding agencies are willing to make further longterm investments in their institutions and disciplines. In the medical departments many positions are announced as shared clinical professorships between the university and the regional hospitals. Hospitals typically bring in most of the funding for universities and decide who to appoint as professors. In a university system that is increasingly dependent on resources from external funders, these types of exemptions, or practices of decoupling, represent a real threat to gender equality. In such instances, candidates tend to be recruited through formal and informal networks and research suggests that men have, on average, more extensive ties to decision-makers than women and typically engage in more gender-homophilic professional relationships (Moore 1990; McGuire 2000; Ibarra 1992).

In summary, the analysis of recruitment and selection practices at Aarhus University demonstrates how women may be at a disadvantage even before the formal assessment of applicants for associate and full professorships begins. Despite a strong belief in meritocracy among the recruiters, pre-selection is prevalent in the hiring practices and women are not always given the same opportunities to compete for the permanent research positions as their men colleagues. This problem cannot be solved solely by making managers and evaluators aware of their unconscious bias. As noted by Husu (2000), this challenge concerns the subtle gender bias embedded in academic networks and women's lower visibility to gatekeepers, compared to their male colleagues.

\section{Standardisation}

The second social process concerns standardisation in academic recruitment and selection. Specifically, this relates to the standardised bibliometric indicators that academic recruiters use to screen their local environments for talent and identify scientific excellence (see Chapter 14). This section draws upon a bibliometric study of 2,000 Danish researchers' publication activities over a three-year period (Nielsen 2017b). Bibliometric measures are advanced analytical tools used to evaluate scholarly productivity and impact. This section demonstrates how this form of standardisation, despite underlying objectives to make performance assessments more transparent and objective, can contribute to the perpetuation of gender inequalities in academic organisations. This often happens in unintended ways, through takenfor-granted organisational routines (Lamont et al 2014; Nielsen 2018).

The empirical example concerns the Danish Bibliometric Research Indicator (BRI) introduced in 2009 by the Danish Ministry of Science, to allocate 
performance-based funding to the Danish Universities. The indicator is based on a differentiated counting of scholarly publications and makes a distinction between prestigious, high quality, journals and book-publishers and normal level publication channels (Table 3.1). When researchers publish in prestigious outlets, their university will receive more indicator points and thereby more funding than when they publish via 'normal level' publication channels.

Table 3.1 The BRI classification model point system by category and level

\begin{tabular}{lll}
\hline & Level 1 (points) & Level 2 (points) \\
\hline Scholarly articles in a journal & 1 & 3 \\
Scholarly articles in an anthology & 0.5 & 2 \\
Scholarly books (ISBN) & 5 & 8 \\
\hline
\end{tabular}

Source: Adapted from Nielsen (2017b).

It is important to note that the Danish bibliometric research indicator was developed to allocate funding for universities, not to measure the performance of individual researchers. The relative amount of university funding allocated based on the indicator is also relatively low. Nevertheless, the indicator is frequently used to measure individual performance, especially in the social sciences and humanities, where standard citation indicators are less applicable (Mouritzen and Opstrup 2020).

A bibliometric analysis based on a stratified sample of more than 2,000 Danish researchers indicated the negative gender consequences of this form of standardisation (Nielsen 2017b). The analysis compared how many indicator points women and men received for their peer-reviewed publications over a three-year period. In regression models, adjusted for scientific field and academic rank, it was observed that women, on average, received notably fewer indicator points per publication than their male colleagues. When scientific performance was measured by counting indicator points instead of counting publications, the average performance gap in favour of men increased from 14 per cent to 20 per cent. This is a relative increase of more than 40 per cent in the gender performance gap. The difference was largest in the social sciences, with a relative increase in the gender performance gap of 50 per cent. This gender bias did not appear to be driven by differences in citation rates and journal impact factors. In 2013, another bibliometric study compared the average field-normalised citation frequencies and journal impact factors of more than 3,000 male and female researchers at Aarhus University. The study showed that women and men, on average, were cited at similar rates, and that the average gender differences in field-normalised impact factor scores were minor. Another study on gender and citation impact in Denmark reached similar conclusions (Frandsen et al 2015).

A more plausible explanation for the increased performance gap caused by the Bibliometric Research Indicator concerns the gender composition of the 68 fieldspecific committees appointed to develop lists of prestigious and less prestigious 
journals and book publishers used in the indicator. These committees primarily consist of reputable researchers at the Danish Universities, of whom many are full professors. In the period covered by this research, only 24 per cent of these researchers were women. In practice, this implies that journals covering methods and topics that fall outside the interest and preferences of a relatively homogenous group of already successful male researchers, risk being undervalued by the indicator. As a result, this standardisation exercise, developed to improve the transparency and objectivity of the universities' performance assessments, ended up introducing a new form of bias into the system. As in the hiring example, this gendered disadvantage does not relate directly to the concept of unconscious bias. Instead, it serves to illustrate how gendered knowledge and status hierarchies can become encapsulated in seemingly objective criteria for evaluating research performance as a form of systemic bias (Nielsen 2017b, 2018). This finding supports Acker's (1990) argument that rationalised performance standards, modelled on the profiles and characteristics of already successful employees, are at high risk of reinforcing gendered status hierarchies.

\section{Symbolic boundary work}

The third and final social process concerns the making and maintenance of symbolic gender boundaries in academic organisations. Epstein described symbolic boundaries as:

the lines that include and define some people, groups, and things while excluding others. They are the conceptual distinctions that people use to categorise each other, for instance, based on gender, race, class or ethnicity.

(Epstein 1992, 232)

To study symbolic boundaries 'is to analyse how social actors construct groups as similar and different and how it shapes their understanding of their responsibilities toward such groups' (Lamont and Molnár 2002, 187). Lamont and Molnár (2002) define such social processes as symbolic boundary work which can be analysed by studying the cultural narratives that people draw upon to make sense of the world around them. For example, how academic managers make sense of the persistent gender imbalances in their departments. Analysing symbolic boundary work can help in understanding how academic managers rationalise gender stereotypes and how such stereotypes contribute to legitimise persistent gender inequalities in hiring and selection.

The empirical example presented here draws on a qualitative analysis of 24 interviews, conducted with department heads at Aarhus University (Nielsen 2017a). In these interviews, the department heads were asked to reflect on what they saw as the main causes of women's under-representation among associate and full professors in their respective departments. Fourteen of the 24 department heads responded by alluding to incompatibilities between the qualities and 
attributes of women researchers and the indispensable requisites of the local research environments. Table 3.2 summarises the prevailing characteristics of the local research environments and the so-called typical male and female attributes and behaviours emphasised by the department heads. Here, women were seen as lacking the necessary self-confidence and competitive spirit to advance in the university's individualistic and competitive work settings, characterised by insecure career paths, high publication pressures and a tough, egoistic machoculture (see Chapters 8 and 14). Furthermore, some department heads emphasised women's need for economic security due to family responsibilities, their lack of interest in management and their lack of international mobility as primary causes of observed gender differences in academic advancement.

Table 3.2 Reflections by department heads on gender roles in the research environment

\begin{tabular}{|c|c|c|}
\hline Research environments & Men's attributes & Women's attributes \\
\hline $\begin{array}{l}\text { Competitive } \\
\text { environment } \\
\text { Individualistic } \\
\text { organisation } \\
\text { (focus on individual } \\
\text { CVs) } \\
\text { Macho culture } \\
\text { High publication } \\
\text { pressure } \\
\text { Science as elite sport } \\
\text { Insecure career path } \\
\text { Tough world } \\
\text { Egoistic } \\
\text { Self-centred } \\
\text { Making big sacrifices } \\
\text { for research } \\
\text { Limitless work time } \\
\text { norms (not a 9-5 } \\
\text { schedule) }\end{array}$ & $\begin{array}{l}\text { Alpha males } \\
\text { Competition-driven } \\
\text { Egoistic } \\
\text { Science as elite sport } \\
\text { (work > family) } \\
\text { More but less } \\
\text { exhaustive } \\
\text { and thorough } \\
\text { publications } \\
\text { Societal structures: } \\
\text { traditionally easier } \\
\text { for men to pursue a } \\
\text { career in academia } \\
\text { 'New type of } \\
\text { men' (holistic/ } \\
\text { network focus/take } \\
\text { responsibility } \\
\text { Live (work) from hand } \\
\text { to mouth } \\
\text { High-speed production }\end{array}$ & $\begin{array}{l}\text { Lack of self-confidence } \\
\text { Shy away from } \\
\text { competition } \\
\text { Need job security } \\
\text { More social } \\
\text { Less egoist } \\
\text { Better at networking } \\
\text { Collectivist approach } \\
\text { Communication } \\
\text { competencies } \\
\text { Family priorities } \\
\text { Need economic } \\
\text { security due to family } \\
\text { responsibilities } \\
\text { Some shy away from } \\
\text { management } \\
\text { More exhaustive and } \\
\text { thorough in their } \\
\text { approach to publications } \\
\text { More holistic worldview } \\
\text { (work-life balance) } \\
\text { Less mobile }\end{array}$ \\
\hline
\end{tabular}

Source: Adapted from Nielsen (2017a)

These statements demonstrate how symbolic gender boundaries are perpetuated in local research environments. Stereotypical assumptions about women's attributes, qualities and interests are symbolically separated from the typical characteristics of the local research environment. In other words, the women are represented as 'soft actors' in a hard world of science, in which the ideal employee is someone who is highly competitive, individualistic, having few commitments outside the workplace (see Chapter 5). Hence, the gender problem becomes a problem relating to individual women rather than the department in its institutional context. In 
Table 3.2 the interviewees also emphasise positive characteristics and qualities that women researchers contribute to their departments. Accordingly, women are more exhaustive and thorough in their publication activities, more collectively oriented, less egoistical and better at communicating than men. These attributes are all critical scientific virtues in a global science system, where teamwork has become the norm (Wuchty et al 2007). However, in the university's individualistic and competitive research environment, they conflict with the image of the ideal employee, and become a gendered disadvantage.

In summary, analysing boundary work as a social process increases the understanding of how gender stereotypes become rationalised in local research environments. It provides insight into the actual content of the assumptions that drive unconscious bias and how specific organisational contexts shape such assumptions. As demonstrated here, some department heads mobilise cultural narratives about the different characteristics and attributes of women and men to account for academic successes and failures in their departments. Consequently, symbolic boundary work contributes to legitimising persistent gender inequalities in hiring and selection.

\section{Promoting equality in academic recruitment and selection}

What can universities do to counter the social processes that perpetuate gender inequalities in academic recruitment and selection? There are four key forms of intervention that emerge from the Danish study. Denmark is a compelling example of the importance of ensuring transparency and continuous oversight in all recruitment and selection activities. Gender bias thrives in situations where recruiters can exploit loopholes to make recruitment and selection run 'fast, cheap and smooth'. Universities need to close these loopholes with the help of administrators and gender equality taskforces. Universities should ensure, through monitoring, that appointments are made based on fair and open procedures and that recruiters are held accountable when this is not the case. Moreover, all research positions should be communicated widely nationally and internationally and university departments should be required to do long-term, transparent scheduling of job announcements. Such scheduling could help to prevent situations whereby vacancies are timed to suit the career progression of specific candidates. Finally, all position profiles should be formulated broadly and should never signal pre-selection through specific requirements.

Previous research (Dobbin and Kalev 2016; Kalev et al 2006; Dobbin et al 2015) provides important insights on the efficacy of diversity programs in promoting workplace equality. Using data from more than 800 US companies over a 30-year period, Dobbin and Kalev (2016) found that appointing diversity task forces and assigning formal responsibilities and authority to diversity managers are two of the most efficient ways to promote gender equality. Task forces and diversity managers hold managers and recruiters accountable for their activities 
by continuously monitoring developments in the representation of women and minorities.

Finally, a recent study by Witteman et al (2019) quantified the negative gender consequences of placing too much emphasis on standardised metrics of performance in academic selection processes. The study was based on data from just over 24,000 research applications to the Canadian Institutes of Health Research. These data allowed the authors to compare women's success rates in two grant programmes. One programme had an explicit review focus on the principal investigator's past performance; the other had a key focus on the quality of the actual research presented in the application. In the grant programme with an explicit focus on past performance, women's likelihood of winning a grant was 30 per cent lower than that of men. In contrast, no clear gender differences in success rates were observed when evaluators focused on the quality of the proposals. An important conclusion from this study, which is relevant for both funding agencies and academic recruiters, is that the explicit focus on past performance, based on bibliometric indices, may lead to indirect gender bias, especially at the early career stages. To avoid this, evaluators need to be instructed to focus more on the quality of the proposed research and less on the characteristics of the researcher.

\section{Conclusion}

This chapter demonstrates that creating change towards gender sensitivity requires in-depth contextualised knowledge about the institutions where change is needed. The focus on unconscious bias in policy and practice is not enough in itself. While most universities in Europe look relatively similar in the proportions of women in professorships, the social processes that perpetuate gender inequalities in research and the obstacles facing women and gender-diverse people, vary considerably across contexts and may change over time (Nielsen 2015b). Continuous research efforts to develop more fine-grained contextualised knowledge about this multifaceted and dynamic problem are therefore crucial.

\section{References}

Acker, J. (1990) Hierarchies, jobs, bodies: A theory of gendered organizations, Gender and Society, 4 (2), 139-158, doi.org/10.1177/089124390004002002

Acker, J. (2006) Inequality regimes: Gender, class, and race in organizations, Gender and Society, 20, (4), 441-464, doi.org/10.1177/0891243206289499

Bielby, W. (2000) Minimizing workplace gender and racial bias, Contemporary Sociology, 29 (1), 233-256, doi.org/10.2307/2654937

Bielby, W. (2013) The challenge of effective interventions: Alternative paths to minimizing workplace gender bias, in Organizational change, Harvard Business School, Boston, 4-11.

Castilla, E. and Bernard, S. (2010) The paradox of meritocracy in organisations, Administrative Science Quarterly, 55 (4), 543-576, doi.org/10.2189/asqu.2010.55.4.543

Correll, S. (2017) SWS 2016 feminist lecture: Reducing gender biases in modern workplaces: A small wins approach to organizational change, Gender and Society, 31 (6), 725-750, doi.org/10.1177/0891243217738518 
Degn, L. (2015) Identity constructions and sensemaking in higher education - a case study of Danish higher education department heads, Studies in Higher Education, 40 (7), 1179-1193, doi.org/10.1080/03075079.2014.881345

Dobbin, F. and Kalev, A. (2016) Why diversity programs fail and what works better, Harvard Business Review, 94 (7-8), 52-60.

Dobbin, F., Schrage, D. and Kalev, A. (2015) Rage against the iron cage: The varied effects of bureaucratic personnel reforms on diversity, American Sociological Review, 80 (5), 1014-1044, doi.org/10.1177/0003122415596416

Epstein, C. F. (1992) Tinkerbells and pinups: The construction and reconstruction of gender boundaries at work, in M. Lamont and M. Fournier (eds), Cultivating differences: Symbolic boundaries and the making of inequality, University of Chicago Press, Chicago.

Frandsen, T., Jacobsen, R., Wallin, J., Brixen, K. and Ousager, J. (2015) Gender differences in scientific performance: A bibliometric matching analysis of Danish health sciences graduates, Journal of Informetrics, 9 (4), 1007-1017, doi.org/10.1016/j.joi.2015.09.006

Haynes, C. and Sweedler, J. (2015) Are we there yet? Biases in hiring women faculty candidates, Analytical Chemistry, 87 (14), 6989, doi.org/10.1021/acs.analchem.5b02454

Husu, L. (2000) Gender discrimination in the promised land of gender equality, Higher Education in Europe, 25 (2), 221-228, doi.org/10.1080/713669257

Ibarra, H. (1992) Homophily and differential returns: Sex differences in network structure and access in an advertising firm, Administrative Science Quarterly, 37 (3), 422-447, doi.org/10.2307/2393451

Kalev, A., Dobbin, F. and Kelly, E. (2006) Best practices or best guesses? Assessing the efficacy of corporate affirmative action and diversity policies, American Sociological Review, 71 (4), 589-617, doi.org/10.1177/000312240607100404

Lamont, M., Beljean, S. and Clair, M. (2014) What is missing? Cultural processes and causal pathways to inequality, Socio-Economic Review, 12 (3), 573-608, doi.org/10.1093/ser/ mwu011

Lamont, M. and Molnár, V. (2002) The study of boundaries in the social sciences, Annual Review of Sociology, 28 (1), 167-195, doi.org/10.1146/annurev.soc.28.110601.141107

López, E. and O'Connor, P. (2019) Micropolitics and meritocracy: Improbable bedfellows? Educational Management Administration and Leadership, 47 (5), 678-693, doi. org/10.1177/1741143218759090

McGuire, G. (2000) Gender, race, ethnicity, and networks: The factors affecting the status of employees' network members, Work and Occupations, 27 (4), 501-524, doi.org/10.1177/ 0730888400027004004

Meyer, J. and Rowan, B. (1977) Institutionalized organizations: Formal structure as myth and ceremony, American Journal of Sociology, 83 (2), 340-363, doi.org/10.1086/226550

Moore, G. (1990) Structural determinants of men's and women's personal networks, American Sociological Review, 55 (5), 726-735, doi.org/10.2307/2095868

Moss-Racusin, C., Dovidio, J., Brescoll, V., Graham, M. and Handelsman, J. (2012) Science faculty's subtle gender biases favor male students, Proceedings of the National Academy of Sciences, 109 (41), 16474-16479, doi.org/10.1073/pnas.1211286109

Mouritzen, P. and Opstrup, N. (2020) Trickling down to the individual, in P. Mouritzen and N. Opstrup (eds), Performance management at universities, Palgrave Macmillan, Cham, 2020, 37-56, doi.org/10.1007/978-3-030-21325-1

Nielsen, M. (2015a) Make academic job advertisements fair to all, Nature, 525 (7570), 427-427, doi.org/10.1038/525427a

Nielsen, M. (2015b) New and persistent gender equality challenges in academia, Politica, Department of Political Science, Aarhus University, Aarhus, Denmark. 
Nielsen, M. (2016) Limits to meritocracy? Gender in academic recruitment and promotion processes, Science and Public Policy, 43 (3), 386-399, doi.org/10.1093/scipol/scv052

Nielsen, M. (2017a) Reasons for leaving the academy: A case study on the 'opt out' phenomenon among younger female researchers, Gender, Work and Organization, 24 (2), 134-155, doi.org/10.1111/gwao.12151

Nielsen, M. (2017b) Gender consequences of a national performance-based funding model: New pieces in an old puzzle, Studies in Higher Education, 42 (6), 1033-1055, doi.org/ $10.1080 / 03075079.2015 .1075197$

Nielsen, M. (2018) Scientific performance assessments through a gender lens, Science and Technology Studies, 31 (1), 2-30, doi.org/10.23987/sts.60610

Reskin, B. and McBrier, D. (2000) Why not ascription? Organizations' employment of male and female managers, American Sociological Review, 65 (2), 210-233, doi. org/10.2307/2657438

Staahle, B. (2014) Videnskabeligt personale på universiteterne 2013, Styrelsen for Videregående Uddannelser, Copenhagen, Denmark.

Uhlmann, E. and Cohen, G. (2007) 'I think it, therefore it's true': Effects of self-perceived objectivity on hiring discrimination, Organizational Behavior and Human Decision Processes, 104 (2), 207-223, doi.org/10.1016/j.obhdp.2007.07.001

Van den Brink, M. (2010) Behind the scenes of science: Gender practices in the recruitment and selection of professors in the Netherlands, Amsterdam University Press, Amsterdam.

Van den Brink, M. and Benschop, Y. (2012) Gender practices in the construction of academic excellence: Sheep with five legs, Organization, 19 (4), 507-524, doi.org/10.1177/ 1350508411414293

Williams, J. and Smith, J. (2015) The myth that academic science isn't biased against women, The Chronicle of Higher Education, 8 July.

Williams, W. and Ceci, S. (2015) National hiring experiments reveal 2:1 faculty preference for women on STEM tenure track, Proceedings of the National Academy of Sciences, 17, 5360-5365, doi.org/10.1073/pnas.1418878112

Witteman, H., Hendricks, M., Straus, S. and Tannenbaum, C. (2019) Are gender gaps due to evaluations of the applicant or the science? A natural experiment at a national funding agency, The Lancet, 393 (10171), 531-540, doi.org/10.1016/S0140-6736(18)32611-4

Wuchty, S., Jones, B. and Uzzi, B. (2007) The increasing dominance of teams in production of knowledge, Science, 316 (5827), 1036-1039, doi.org/10.1126/science.1136099 